\title{
Carbon emissions performance in logistics at the city level
}

\author{
Junai Yang ${ }^{\mathrm{a}}$, Ling Tang ${ }^{\mathrm{a}, *}$, Zhifu Mib ${ }^{\mathrm{b}, *}$, Sen Liu' ${ }^{\mathrm{c}}$, Ling $\mathbf{L i}^{\mathrm{d}}$, Jiali Zhengbe,f \\ ${ }^{a}$ School of Economics and Management, Beihang University, Beijing 100191, China \\ ${ }^{\mathrm{b}}$ The Bartlett School of Construction and Project Management, University College London, London WC1E 7HB, \\ UK \\ ${ }^{c}$ School of Logistics, Yunnan University of Finance and Economics, Kunming 650221, China \\ d International School of Economics and Management, Capital University of Economics and Business, Beijing, \\ 100070, China \\ ${ }^{\mathrm{e}}$ Academy of Mathematics and Systems Science, Chinese Academy of Sciences, Beijing 100190, China \\ ${ }^{\mathrm{f}}$ School of Economics and Management, University of Chinese Academy of Sciences, Beijing 100190, China
}

\section{Highlights:}

- We investigate carbon emissions performance in logistics at the city level.

- An empirical study on sixteen cities in China is conducted.

- Logistics-related carbon emissions of sixteen cities have increased from 2011 to 2015.

- Carbon emissions performance in logistics vary across cities.

- Carbon emissions performance in logistics attributes to different driving factors.

\begin{abstract}
The importance of good performance in the logistics industry contributing towards a lowcarbon economy is widely recognized. However, there are few studies on carbon emissions performance for the logistics industry, especially at the city level. Therefore, this study attempts to analyse the carbon emissions performance of the logistics industry at the city level by examining sixteen cities within Yunnan Province. In particular, the Data envelopment analysis (DEA) model and Malmquist Index from both the static and dynamic perspective were explored. To further capture the driving factors of the carbon emissions performance in logistics, the Tobit model was applied to perform regression analysis. The results indicate that (1) with regards to static
\end{abstract}

\footnotetext{
${ }^{*}$ Corresponding authors.

E-mail address: lingtang@buaa.edu.cn (L. Tang), E-mail address: z.mi@ucl.ac.uk (Z. Mi)
} 
performance, two northwest cities, Nujiang and Diqing, have reached the technological frontier; (2) regarding dynamic performance, although six cities have improved, the average dynamic logistics carbon emissions performance of all the cities decreases by approximately $5.9 \%$ from 2011 to 2015; (3) in terms of driving factors, the economic development factor is found to be positively and significantly related to static carbon emissions performance, whereas others indicate negative and significant relationships.

Keywords: Carbon emissions performance; Logistics industry; City level; Data envelopment analysis; Malmquist index

\section{Introduction}

Energy consumption in China has increased rapidly due to continuous economic growth (Dong et al., 2017). More specifically, China's energy consumption increased from approximately 1,359 million tons of standard coal equivalent (Mt) in 1997 to 4,299 Mt in 2015, with an increase in GDP from 7,971 billion yuan to 68,905 billion yuan, respectively (National Bureau Statistics of China, 2018). As a result, China's carbon emissions increased significantly from 3,309 Mt to 11,603 Mt during this period (Shan et al., 2018), and China became the world's largest emitter of carbon dioxide since 2006 (Mi et al., 2017). Based on China's energy structure, the logistics industry has become one of the largest and most important energy consumers and contributors of carbon emissions. According to the China Energy Statistical Yearbook, the logistics industry's energy consumption has increased dramatically, from 58.63 Mt in 1995 to $383.18 \mathrm{Mt}$ in 2015, which accounts for approximately $10 \%$ of China's total energy consumption. Therefore, the logistics industry is influential in reducing energy consumption and mitigating carbon emissions.

The logistics industry contains a range of activities involved in moving products from the point of origin, through the production system and on to the point of consumption to meet the requirements of customers or corporations (Mckinnon and Piecyk, 2012). For the logistics industry, transport and warehouse are clearly core activities and are also important sources of emission savings. Throughout the most recent decade, China has focused on carbon emissions mitigation, especially in the logistics industry. For corresponding government planning, "green and low-carbon logistics development" has been explored in China through the announcement of several new energy 
and carbon emissions goals, and an emission offset plan that aims to reduce energy consumption and carbon emissions by road transport operators has been issued by China's Ministry of Transport (Zhang et al., 2015).

As one of China's low-carbon economy pilot programmes and the radiation centre of Southern and Southeast Asia, the Yunnan provincial government noted the necessity of developing lowcarbon logistics in its 12th and 13th Five-Year Plans. According to the Yunnan Statistical Yearbook, the output of the logistics industry in Yunnan Province has increased by 40\%, from 21,722 million yuan in 2005 to 30,449 million yuan in 2014 , and the growth rate of energy consumption in logistics has been approximately $80 \%$, from $570.30 \mathrm{Mt}$ to $1032.41 \mathrm{Mt}$ during the same period. Since the cities in Yunnan Province vary greatly based on their development stage, industry composition and geographical conditions, their energy consumption and carbon emissions are also variable. Therefore, further investigation into carbon emissions mitigation in the logistics industry based on these different cities provides opportunities for the advancement of a low-carbon economy.

According to existing studies, carbon emissions performance has been widely analysed in different sectors. Analysing carbon emissions performance in the industrial sector represents a growing trend; these studies focus mainly on electricity generation or fossil fuel power plants (Wang and Du, 2017; Yan et al., 2017; Zhang et al., 2013). Researchers have also investigated other sectors, such as agriculture (Fei and Lin, 2016; Lin and Fei, 2015) and construction (Hu et al., 2017). Regarding the logistics industry, although there have been numerous studies focusing on its carbon emissions (Tian et al., 2018; Behnke and Kirschstein, 2017; Li and Tang, 2018), the research on its carbon emissions efficiency or performance is rare (Zhang et al., 2015). Moreover, from the perspective of spatial scale, carbon emissions performance has typically been analysed at the national or provincial level (Wu et al., 2018; Lin and Du, 2015; Zhou et al., 2014; Zhou and Wang, 2012), whereas research at the city level is insufficient (Li et al., 2018; Mariano et al., 2017). It is generally true that cities are the basic components of administrative regions, and they are critical for implementing carbon emissions mitigation policies (Mi et al., 2019a). Studying cities' carbon emissions and their performance is fundamental to proposing mitigation actions. Although a few studies have focused on different cities' carbon emissions, such as Mi et al. (2016), Cai et al. (2018), Zhang et al. (2018) and Mi et al. (2019b), more work remains to be done on carbon emissions 
efficiency and climate policy analysis, particularly for new and different cities. Therefore, this study fills the literature gap by exploring the carbon emissions performance in the logistics industry at the city level.

In the research field of carbon emissions performance, combining DEA with the Malmquist index is a dominant and effective method (Lin and Fei, 2015; Mariano et al., 2017; Zhang and Choi, 2013a). Compared with other efficient approaches, DEA has the following advantages. First, it can be used to avoid the assumptions of measurement functional forms and prior conditions (MolinosSenante et al., 2016). Second, it does not require the same measurement units for all variables and can clearly identify benchmark technologies (Hu et al., 2017). Third, it can identify the best-practice technologies and inefficient DMUs by comparing every individual production technology. However, the DEA method can only capture the static carbon emissions performance, whereas combined with the Malmquist index, it can be used to measure dynamic carbon emissions performance. Malmquist is an index determined by the distance of DMUs from efficiency scores (Caves et al., 1982; Malmquist, 1953). This index measures productivity changes over time and can be calculated using the DEA model (Mariano et al., 2017). Moreover, the Malmquist index is decomposed into efficiency change and technological change, which can identify the factors for performance change. Therefore, this paper explores DEA and the Malmquist index to measure carbon emissions performance in logistics from both a static and a dynamic perspective.

Furthermore, carbon emissions, as an undesirable output, can be managed by DEA using three approaches (Wu et al., 2018). The first approach treats the undesirable outputs as inputs, based on the economic argument that this approach violates the law of mass conservation; the second approach introduces an abatement factor reflecting the weak disposability between desirable and undesirable outputs, known as Shephard production; and the third approach transforms the data of undesirable outputs and then uses the conventional efficiency evaluation mode (Seiford and Zhu, 2002; Zhou et al., 2013; Zhou et al., 2018). By comparison, the third approach (i.e., data transformation approach) can be applied to treat the undesirable outputs in the standard linear DEA model (i.e., $\mathrm{BC}^{2}$-DEA). Therefore, this study introduced the data transformation approach into the $\mathrm{BC}^{2}$-DEA model to address undesirable outputs.

In this study, we first estimate the carbon emissions in the logistics industry for sixteen cities 
within Yunnan Province. Second, we explore the $\mathrm{BC}^{2}$-DEA model and Malmquist index to measure the carbon emissions performance in the logistics industry from both a static and dynamic perspective. Finally, we capture the driving factors of carbon emissions performance in logistics. Relative to existing research, this study makes major contributions in the following two areas: (1) it attempts to investigate carbon emissions performance in logistics at the city level, and (2) it examines sixteen cities in Yunnan Province as a case study to measure their carbon emissions performance in the logistics industry.

The remainder of the paper is organized as follows. Section 2 presents the methodology, which consists of carbon emissions estimation, environmental DEA technology, the Malmquist Index and the Tobit regression model. Section 3 describes the data used in the empirical study. In Section 4, the carbon emissions performance in logistics and related contributing factors for sixteen cities in Yunnan Province are examined from 2011 to 2015. Finally, Section 5 presents the conclusions and policy implications.

\section{Methodology}

To measure carbon emissions performance in the logistics industry, it is important to calculate the logistics carbon emissions. At present, the carbon emissions monitoring data for China's logistics industry is insufficient, and there are no carbon emissions data for the logistics industry in Yunnan Province. Therefore, we calculate the logistics industry's carbon emissions for sixteen cities within Yunnan Province in Subsection 2.1. Moreover, we measure the logistics industry's carbon emissions performance for these sixteen cities based on the $\mathrm{BC}^{2}$-DEA model and Malmquist index from both a static and dynamic perspective, which are introduced and described in Subsections 2.2 and 2.3. Finally, we introduce a Tobit regression model to conduct regression analysis in Subsection 2.4. 


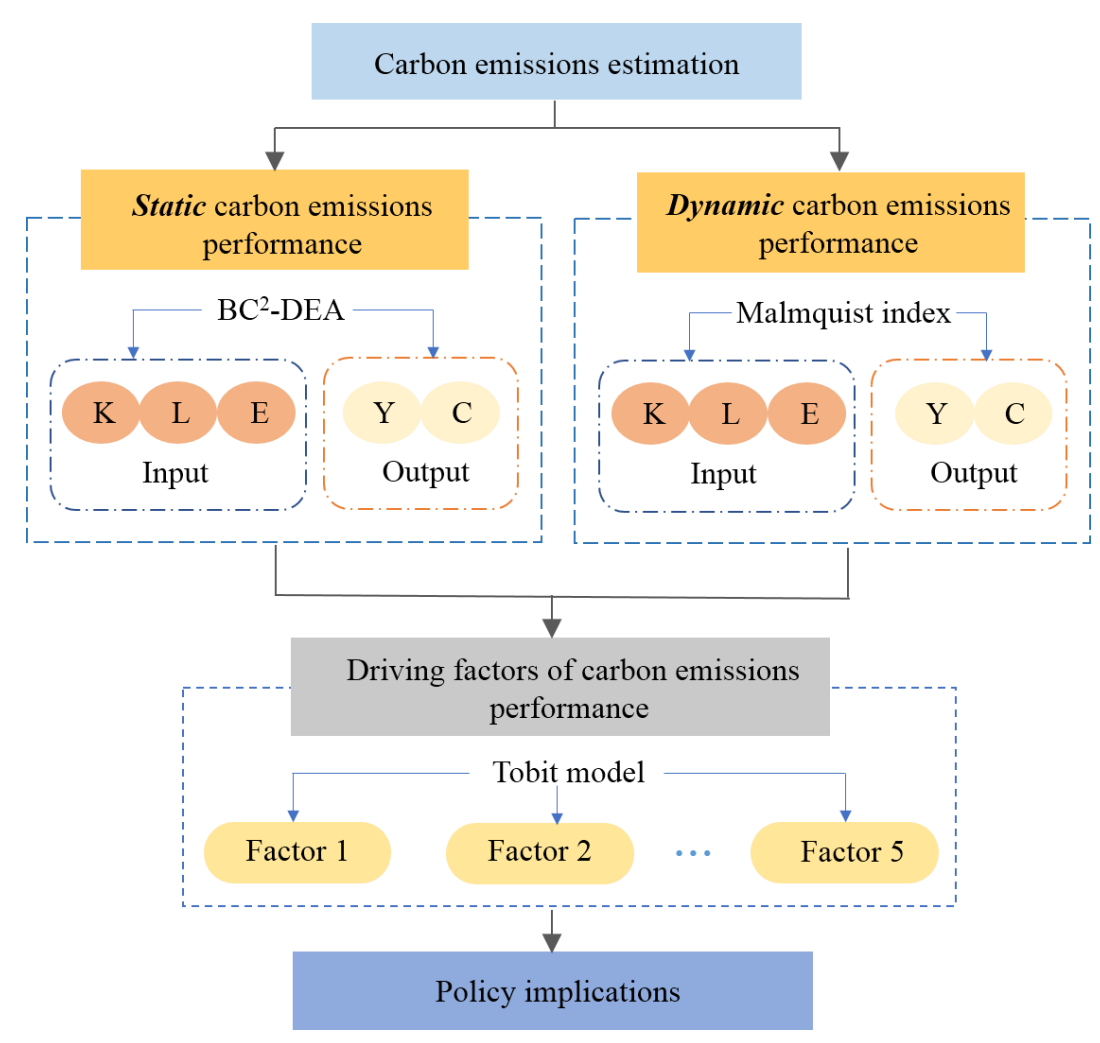

Fig. 1. The framework of carbon emissions performance analysis in logistics.

\subsection{Carbon emissions estimation}

According to the method provided by IPCC (2006), we calculate the carbon emissions from each energy consumption and then sum these values according to the following equation:

$$
C O_{2}=\sum_{i=1}^{n} C O_{2 i}=\sum_{i=1}^{n} E_{i} \times N C V_{i} \times C E F_{i} \times C O F_{i} \times(44 / 12),
$$

where $\mathrm{CO}_{2}$ is the estimated value, $E$ signifies the consumption of energy, $\mathrm{NCV}$ represents the average low calorific value, $C E F$ is the carbon emission coefficient, $C O F$ denotes the carbon oxidation factor, and 44 and 12 represent the molecular weight of carbon dioxide and carbon, respectively. The value of the carbon oxidation factor $(C O F)$ is 1 in IPCC (2006). Considering the energy consumption structure of the logistics industry, we use the following energy types to estimate the logistics industry's carbon emissions (Zhou et al., 2013). 
Table 1 The average low calorific value and carbon emission coefficient for five different energy types.

\begin{tabular}{llllll}
\hline Energy type & Raw coal & Gasoline & Kerosene & Diesel oil & Natural gas \\
\hline $\begin{array}{l}\text { Average low calorific value } \\
(\mathrm{kJ} / \mathrm{kg})\end{array}$ & 20908 & 43070 & 43070 & 42652 & 38931 \\
Carbon emission coefficient & 25.8 & 18.9 & 19.6 & 20.2 & 15.3 \\
$(\mathrm{~kg} \mathrm{C} / \mathrm{GJ})$ & & & & & \\
\hline
\end{tabular}

Source: Yunnan Energy Statistical Yearbook “2014-2015” and IPCC (2006).

In our model, carbon emissions are an undesirable output that must be reduced. However, in a traditional DEA model, a higher output is expected. Therefore, we use a data transformation approach to manage the undesirable outputs (Seiford and Zhu, 2002). Technically, assuming there are $j=1,2, \cdots, 16$ cities, for each city $j$, the logistics carbon emissions for a specific year k is $C_{k j}$, and the maximal logistics carbon emissions among all cities in a year is $\max \left(C_{k}\right)$. Note that $\eta=$ $\max \left(C_{k}\right)+1$; thus, the transformed desirable output is $C_{k j}^{*}=\eta-C_{k j}$, where $C_{k j}^{*} \geq 1$. Through the data transformation approach, the undesirable output that must be reduced was transformed to a desirable output that is expected to increase.

\subsection{Environmental DEA technology}

When using DEA to measure logistics carbon emissions performance with undesirable outputs, we first must introduce environmental production technology. Assume that each decision-making unit (DMU), i.e., the sixteen cities in Yunnan Province, employs capital stock $(K)$, labour force $(L)$ and energy consumption $(E)$ as inputs to produce added value $(Y)$ and carbon emissions $(C)$ as the single desirable output and undesirable output, respectively. The environmental production technology $T$ can be described as:

$$
f(K, L, E)=\{(Y, C):(K, L, E, Y, C) \in T\}
$$

where $T$ denotes the environmental production technology, focusing on a specific input-output process, and $f(K, L, E)$ is a production set that represents all possible outputs (Fare and Grosskopf, 2003). 
In production economic theory, $T$ is typically assumed to be a closed and bounded set in which finite inputs can only generate finite outputs. In addition, the inputs $(K, L, E)$ and the desirable outputs $(Y)$ are often supposed to be strongly or freely disposable. This implies that the desirable output can be freely reduced using the same amount of inputs or the inputs can be freely increased using the same amount of outputs. Moreover, two additional assumptions, i.e., weak disposability and null-jointness, must be imposed to make the production technology more reasonable (Fare et al., 1989). Technically, the two assumptions can be formulated as:

(a) if $(K, L, E, Y, C) \in T$ and $0 \leq \theta \leq 1$, then $(K, L, E, \theta Y, \theta C) \in T$

(b) if $(K, L, E, Y, C) \in T$ and $C=0$, then $Y=0$

The weak disposability assumption (a) implies that the reduction of undesirable output will cause the same proportion of reduction on desirable output. The null-jointness assumption (b) implies that it is inevitable to generate undesirable output in the production process and the only way to remove all undesirable output is to discontinue production activities.

To achieve a better understanding of environmental production technology and apply it to specific empirical studies, researchers have attempted to characterize the environmental production technology within the DEA framework (Lin and Fei, 2015; Zhou et al., 2014). Specifically, using DEA enables a strong disposability between inputs and desirable outputs to be clearly expressed by constrained inequalities, and a weak disposability and null-jointness between inputs and undesirable outputs can be represented by the relationship equation. Thus, DEA has gained considerable popularity in environmental production technology and researchers have termed it an environmental DEA technology (Cheng and Shi, 2018; Wu et al., 2012).

As for the DEA model, this paper uses BC ${ }^{2}$-DEA based on the research of Banker et al. (1984). Suppose there are $j=1,2, \cdots, 16$ cities, and for each city $j$ the vector of inputs and desirable and undesirable outputs of the logistics industry are $\left(K_{j}, L_{j}, E_{j}, Y_{j}, C_{j}\right)$. The environmental DEA technology exhibiting variant returns of scale based on input-orientation can be described as follows:

$$
\begin{aligned}
& \min \theta \\
& \text { s.t. } \sum_{j=1}^{n} \lambda_{j} K_{j}+S^{-} \leq \theta K \\
& \sum_{j=1}^{n} \lambda_{j} L_{j}+S^{-} \leq \theta L
\end{aligned}
$$




$$
\begin{aligned}
& \sum_{j=1}^{n} \lambda_{j} E_{j}+S^{-} \leq \theta E \\
& \sum_{j=1}^{n} \lambda_{j} Y_{j}-S^{+} \geq Y \\
& \sum_{j=1}^{n} \lambda_{j} C_{j}=C \\
& \lambda_{j} \geq 0, S^{-} \geq 0, \mathrm{~S}^{+} \geq 0, j=1,2, \ldots 16 .
\end{aligned}
$$

In this model, $\theta$ is the DMU efficiency, and $S^{-}$and $S^{+}$are slack variables. $\lambda_{j}$ refers to the intensity levels at which the DMUs conduct production activities, and it provides the weights for constructing the environmental DEA technology. The model attempts to reduce the input to the greatest extent, whereas the resulting input must be less than or equal to the current level (Eqs. (3a), (3b) and (3c)); the resulting desirable output must be at least the same as the current level (Eq. (3d)); and the resulting undesirable output remains the same (Eq. (3e)).

This paper uses the $\mathrm{BC}^{2}$-DEA model to measure the static carbon emissions performance in the logistics industry, represented by the static carbon emissions performance index (SCPI). The SCPI describes the ratio of potential carbon emissions to actual carbon emissions. Specifically, a larger SCPI indicates better logistics carbon emissions performance, and when SCPI $=1$, the city arrived at the current technological frontier. The SCPI can be decomposed into pure technical efficiency $(\mathrm{PTE})$ and scale efficiency $(\mathrm{SE})$. Mathematically, SCPI $=\mathrm{PTE} \times \mathrm{SE}$.

\subsection{Malmquist index}

The Malmquist index, which was inspired by Malmquist (1953) and developed by Caves et al. (1982), is an index number determined by the distances of DMUs from the efficiency scores. Fare et al. (1994) extend the Malmquist index by decomposing productivity growth into changes in efficiency and changes in technology with nonparametric programming methods. Since then, the Malmquist index has been widely applied in different areas. For environmental studies, Zhou et al. (2010) proposed a Malmquist carbon emissions performance index to measure the total carbon emissions performance of the world's 18 top $\mathrm{CO}_{2}$ emitters within environmental DEA technology. 
Empirical studies of such issues using the Malmquist index can be found in Zhang et al. (2015), Emrouznejad and Yang (2016), Mariano et al. (2017), Houshyar et al. (2017) and Wang and Li (2018).

Following the spirit of the Malmquist index, we propose a DCPI for evaluating the change in logistics carbon emissions performance over the period 2011-2015. In this paper, we measure the logistics carbon emissions performance of each city in Yunnan Province and employ capital stock $(\mathrm{K})$, labour force $(\mathrm{L})$ and energy consumption $(\mathrm{E})$ as inputs to produce logistics value added $(\mathrm{Y})$ and carbon dioxide emissions $(\mathrm{C})$ as the outputs. In accordance with the Malmquist index developed by Fare et al. (1994), we define the dynamic carbon emissions performance index (DCPI) as follows:

$$
D C P I_{j}^{t, t+1}=\left[\frac{D_{j}^{t+1}\left(K^{t+1}, L^{t+1}, E^{t+1}, Y^{t+1}, C^{t+1}\right)}{D_{j}^{t}\left(K^{t}, L^{t}, E^{t}, Y^{t}, C^{t}\right)} \times \frac{D_{j}^{t}\left(K^{t+1}, L^{t+1}, E^{t+1}, Y^{t+1}, C^{t+1}\right)}{D_{j}^{t+1}\left(K^{t}, L^{t}, E^{t}, Y^{t}, C^{t}\right)}\right]^{\frac{1}{2}}
$$

In Eq. (4), $t$ indicates the time periods and $j$ represents each city. This equation measures the dynamic changes of performance from the $t$ period to the $t+1$ period. If the value of the $D C P I$ is greater than 1 , that indicates improvements in performance from year $t$ to year $t+1$; if the value is less than 1 , that denotes regression or deterioration in the relevant performance ; if the value is equal to 1 , that indicates that the performance remained constant during the period and maintained its original level. Similar to the Malmquist index, the DCPI can be decomposed into two components: changes in efficiency $(\mathrm{ECH})$ and changes in technology $(\mathrm{TCH})$.

$$
\begin{gathered}
E C H_{j}^{t, t+1}=\frac{D_{j}^{t+1}\left(K^{t+1}, L^{t+1}, E^{t+1}, Y^{t+1}, C^{t+1}\right)}{D_{j}^{t}\left(K^{t}, L^{t}, E^{t}, Y^{t}, C^{t}\right)}, \\
T C H_{j}^{t, t+1}=\left[\frac{D_{j}^{t}\left(K^{t}, L^{t}, E^{t}, Y^{t}, C^{t}\right)}{D_{j}^{t+1}\left(K^{t}, L^{t}, E^{t}, Y^{t}, C^{t}\right)} \times \frac{D_{j}^{t}\left(K^{t+1}, L^{t+1}, E^{t+1}, Y^{t+1}, C^{t+1}\right)}{D_{j}^{t+1}\left(K^{t+1}, L^{t+1}, E^{t+1}, Y^{t+1}, C^{t+1}\right)}\right]^{\frac{1}{2}},
\end{gathered}
$$

where the ratio outside the brackets measures the efficiency change between years $t$ and $t+1$, i.e., the change in how far observed production is from maximum potential production. The geometric mean of the two ratios inside the brackets captures the technology change between the two periods evaluated at $x^{t}$ and $x^{t+1}$, i.e., the movement of the production frontier under the influence of technological progress. 


\subsection{Tobit regression model}

The Tobit regression model, which was proposed by Tobin (1958), indicates the association between a non-negative dependent variable (latent variable) and independent variable (s) when the data are censored or truncated (Saglam, 2018). The values of SCPI are between 0 and 1, and the values of DCPI are greater than 0 . There is a minimum value limit of 0 , which is the truncated data. If the performance value is regarded as a dependent variable, a general ordinary least square (OLS) estimation method leads to biased and inconsistent estimating results (Wang et al., 2017). Therefore, the Tobit model has been widely used for analysing driving factors of energy and environmental performance (Feng et al., 2017). In this study, we use the Tobit regression model to analyse the driving factors of carbon emissions performance in logistics. The model is as follows (Tobin,1958):

$$
Y=\left\{\begin{array}{ll}
Y^{*}=\beta X+\mu & Y^{*}>0 \\
0 & Y^{*} \leq 0
\end{array},\right.
$$

where $\beta$ is a vector of unknown coefficients that depicts the relationship between the vector of independent variables $(X)$ and the latent variable $\left(Y^{*}\right)$, and $\mu$ is the stochastic error that yields to $N\left(0, \sigma_{\mu}^{2}\right)$.

\section{Data}

The data, spanning from 2011-2015, was primarily based on the Yunnan Statistical Yearbook and the Yunnan Energy Statistical Yearbook. In this study, sixteen cities in Yunnan Province are examined as a case study to measure carbon emissions performance in logistics. Table 2 shows the socio-economic information of these sixteen cities in 2015. The data for population and gross regional product (GRP) of each city were taken from Yunnan Statistical Yearbook, and the data for area were collected from the government's official website for each city. 
Table 2 Socio-economic information for sixteen cities in 2015.

\begin{tabular}{|c|c|c|c|}
\hline City & Population (Million) & Area $\left(\mathrm{km}^{2}\right)$ & GRP (Million yuan) \\
\hline Kunming & 6.67 & 21,473 & 396,801 \\
\hline Qujing & 6.04 & 28,900 & 163,026 \\
\hline Yuxi & 2.36 & 15,000 & 124,452 \\
\hline Baoshan & 2.58 & 19,630 & 55,196 \\
\hline Zhaotong & 5.43 & 23,021 & 70,838 \\
\hline Lijiang & 1.28 & 20,600 & 28,961 \\
\hline Puer & 2.60 & 45,000 & 51,401 \\
\hline Lincang & 2.50 & 24,000 & 50,212 \\
\hline Chuxiong & 2.73 & 28,438 & 76,297 \\
\hline Honghe & 4.65 & 32,931 & 122,108 \\
\hline Wenshan & 3.60 & 31,456 & 67,004 \\
\hline Xishuangbanna & 1.16 & 19,124 & 33,591 \\
\hline Dali & 3.54 & 29,459 & 90,010 \\
\hline Dehong & 1.27 & 11,500 & 29,232 \\
\hline Nujiang & 0.54 & 14,703 & 11,315 \\
\hline Diqing & 0.40 & 23,870 & 16,114 \\
\hline
\end{tabular}

We now employ models described in Section 2 to examine the logistics carbon emissions performance and its driving factors for sixteen cities within Yunnan Province. Specifically, we use the investment in fixed assets, number of employees and energy consumption data within the logistics industry to represent the capital stock (K), labour force (L) and energy (E), respectively. Regarding output, we use gross product in the logistics to indicate desirable output (Y) and choose carbon emissions in the logistics as undesirable output (C) (Feng et al., 2017; Zhang et al., 2015). It should be noted that the data quality and statistical specifications in China's logistics industry are different from international standards, for instance, data on the transport and postal service are collected together ( $\mathrm{Li}$ and Tang, 2017). Moreover, data directly related to the logistics industry in China's Statistical Yearbooks, especially at the city level, is limited. Since transport and 
warehousing are relatively core activities and are important sources of emission savings in logistics, we use the data for transport, storage, and postal industries recorded in China's Statistical Yearbooks to represent the logistics industry in this paper (Zhou et al., 2013).

To analyse the driving factors of logistics carbon emissions performance, we consider several factors. First, economic development is analysed because the relationship between economic growth and carbon emissions has been widely recognised (Zhang and Choi, 2013b). Second, energy intensity, which measures an economy's energy efficiency, is calculated as units of energy per unit of GDP. Third, since the movement of the rural population to the cities can accelerate the growth in the usage of energy and transport (Wang and Ma, 2018), urbanization is considered a driving factor. Fourth, endowment structure is used, as it can reflect the relationship between capital, labour and energy. Endowment structure can be defined as the ratio of capital to labour. If the value is low, it indicates that the regional logistics type tends to be labour-intensive; otherwise, it tends to be capitalintensive (Cheng and Shi, 2018). Finally, technology is considered because technological progress promotes industrial productivity and may affect logistics carbon emissions performance. In this paper, we use R\&D expenditure to represent technological progress. The information on driving factors is presented in Table 3 .

Table 3 Definitions and data source for the five driving factors.

\begin{tabular}{lll}
\hline Driving factor & Definition & Data source \\
\hline Economic development & GDP per capita of each city & Yunnan Statistical Yearbook (2012-2016) \\
Energy intensity & $\begin{array}{l}\text { Logistics energy consumption divided } \\
\text { by logistics gross product }\end{array}$ & $\begin{array}{l}\text { Yunnan Energy Statistical Yearbook } \\
(2014-2015)\end{array}$ \\
Urbanization level & $\begin{array}{l}\text { Urban inhabitants divided by total } \\
\text { population }\end{array}$ & Yunnan Statistical Yearbook (2012-2016) \\
Endowment structure & $\begin{array}{l}\text { Value of investment in fixed assets } \\
\text { divided by the number of employees }\end{array}$ & Yunnan Statistical Yearbook (2012-2016) \\
Technological progress & R\&D expenditure of each city & Yunnan Statistical Yearbook (2012-2016) \\
\hline
\end{tabular}




\section{Results and discussions}

\subsection{Carbon emissions in logistics}

The results in Table 4 show that the logistics carbon emissions for the sixteen cities in Yunnan Province have increased throughout the research period. In 2011, carbon emissions were greater than 100 (10 tons) for only 30\% of the cities (Kunming, Qujing, Yuxi, Honghe and Dali) in the logistics industry. However, in 2015, the rate had increased to 50\% (Kunming, Qujing, Yuxi, Zhaotong, Chuxiong, Honghe, Wenshan and Dali). Furthermore, Kunming has the highest level of carbon emissions in the logistics industry, with 457.52 (10 tons) in 2011 and $522.16\left(10^{4}\right.$ tons) in 2015, whereas Nujiang has the lowest levels of carbon emissions, with 14.34 ( $10^{4}$ tons) in 2011 and 20.74 ( $10^{4}$ tons) in 2015. As shown in Fig. 2, a large proportion of carbon emissions in the logistics industry is produced within developed cities. For example, an intensive logistics-related carbon emissions area is located in eastern and central Yunnan Province, containing Kunming, Qujing, Yuxi and Honghe, whose GRP all exceeded 100,000 million yuan, as shown in table 2. However, logistics-related carbon emissions are lower in western Yunnan Province, such as in Nujiang and Diqing, located in remote and less economically developed areas with GRP 11,315 and 16,114 million yuan, respectively. 
Table 4 Logistics carbon emissions (104 tons) of 16 cities within Yunnan Province during 2011-2015.

\begin{tabular}{|c|c|c|c|c|c|}
\hline City & 2011 & 2012 & 2013 & 2014 & 2015 \\
\hline Kunming & 457.52 & 501.16 & 469.88 & 480.50 & 522.16 \\
\hline Qujing & 305.71 & 347.39 & 336.78 & 334.86 & 375.12 \\
\hline Yuxi & 220.32 & 238.80 & 219.55 & 222.01 & 241.31 \\
\hline Baoshan & 62.59 & 70.06 & 67.32 & 72.96 & 80.70 \\
\hline Zhaotong & 92.68 & 103.56 & 98.68 & 99.11 & 108.93 \\
\hline Lijiang & 39.90 & 45.04 & 43.44 & 42.39 & 47.89 \\
\hline Puer & 53.69 & 60.54 & 58.15 & 61.58 & 68.61 \\
\hline Lincang & 36.69 & 42.19 & 40.75 & 44.64 & 50.70 \\
\hline Chuxiong & 89.81 & 97.92 & 91.21 & 94.20 & 102.06 \\
\hline Honghe & 216.68 & 237.00 & 221.99 & 234.01 & 256.03 \\
\hline Wenshan & 79.40 & 88.43 & 84.69 & 91.32 & 102.06 \\
\hline Xishuangbanna & 27.05 & 30.27 & 29.42 & 32.43 & 36.36 \\
\hline Dali & 117.47 & 130.16 & 122.78 & 127.13 & 139.12 \\
\hline Dehong & 38.95 & 42.19 & 42.82 & 42.59 & 50.92 \\
\hline Nujiang & 14.34 & 15.52 & 17.18 & 18.36 & 20.74 \\
\hline Diqing & 17.80 & 20.17 & 19.31 & 21.02 & 23.62 \\
\hline
\end{tabular}




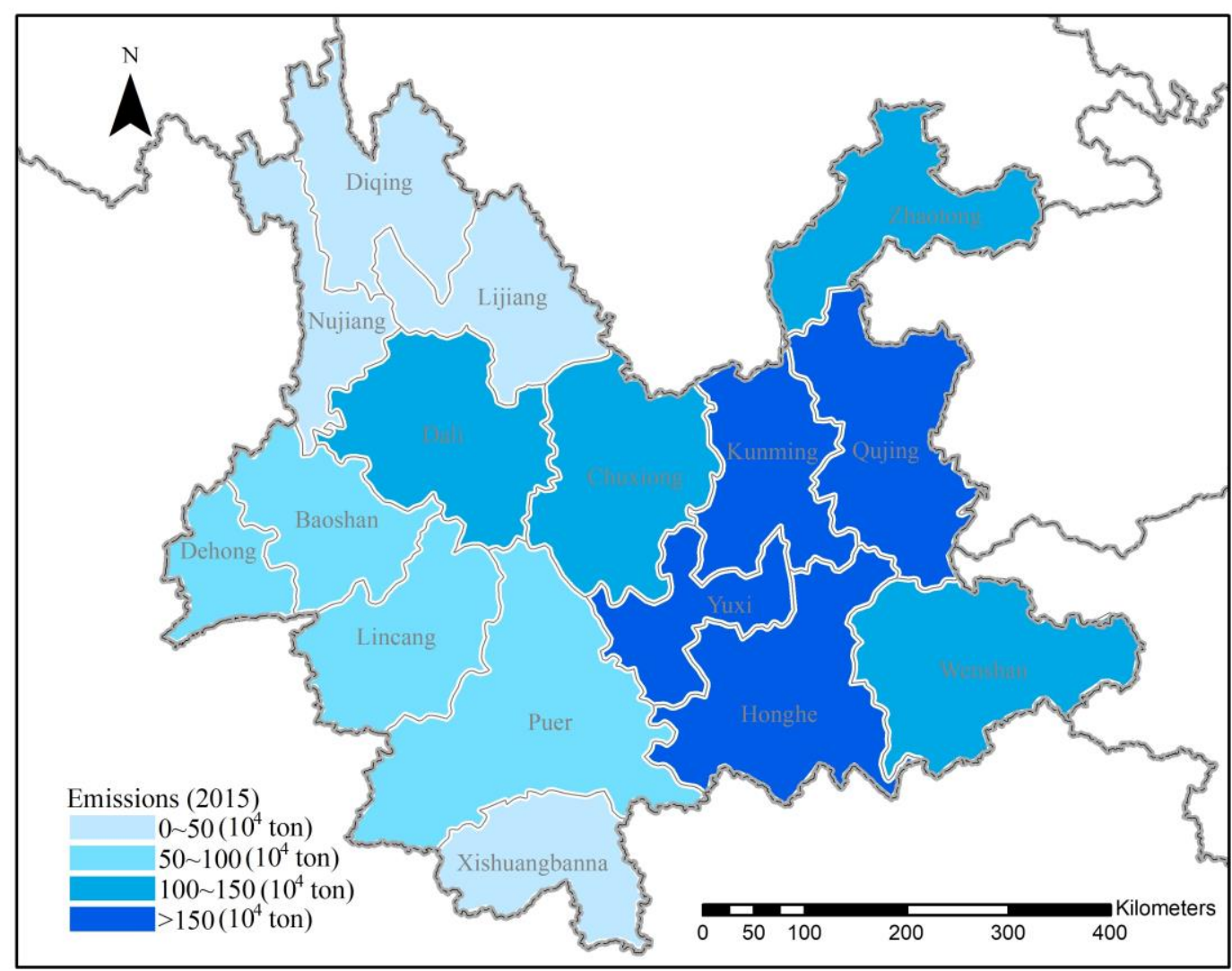

Fig. 2. Logistics carbon emissions of 16 cities within Yunnan Province in 2015.

\subsection{Static carbon emissions performance in logistics}

Table 5 shows the empirical results of the static carbon emissions performance index (SCPI) in the logistics industry from 2011 to 2015. According to the calculated results from sixteen cities, we find that Nujiang and Diqing have always been benchmarks for the technological frontier during the whole period, having achieved the best carbon emissions performance in logistics. Nujiang and Diqing are located in northwestern Yunnan Province, where the ecological environment is excellent, and the population is sparse ( 0.54 and 0.40 million people, respectively). The smaller economies and minimal amount of logistics-related carbon emissions might have resulted in better performances for these two cities. However, Honghe, which is an important chemical base in Yunnan Province, had the lowest SCPI (its average SCPI is 0.42) from 2011 to 2015. As an essential part of the chemical industry, logistics in Honghe contributed to higher energy consumption. Thus, 
energy consumption and pollution-intensive development might have caused a lower SCPI in Honghe. This factor also indicates that there is considerable potential for Honghe to improve its carbon emissions performance in logistics. Other cities, such as Yuxi, Xishuangbanna, Dali and Dehong, have good performance levels, i.e., the SCPI of these cities reach the technological frontier most of the time.

Table 5 Static logistics carbon emissions performance index (SCPI) for sixteen cities.

\begin{tabular}{|c|c|c|c|c|c|}
\hline City & 2011 & 2012 & 2013 & 2014 & 2015 \\
\hline Kunming & 0.467 & 0.550 & 0.563 & 0.649 & 0.778 \\
\hline Qujing & 1.000 & 1.000 & 0.762 & 0.835 & 0.854 \\
\hline Yuxi & 1.000 & 1.000 & 1.000 & 0.751 & 0.816 \\
\hline Baoshan & 0.799 & 1.000 & 1.000 & 0.733 & 0.836 \\
\hline Zhaotong & 0.583 & 0.644 & 0.682 & 0.602 & 0.734 \\
\hline Lijiang & 0.585 & 0.708 & 0.568 & 1.000 & 1.000 \\
\hline Puer & 0.574 & 0.597 & 0.584 & 0.661 & 0.731 \\
\hline Lincang & 0.575 & 0.565 & 0.559 & 0.577 & 0.649 \\
\hline Chuxiong & 0.731 & 0.901 & 0.828 & 0.814 & 0.985 \\
\hline Honghe & 0.287 & 0.327 & 0.383 & 0.559 & 0.558 \\
\hline Wenshan & 0.610 & 0.763 & 0.797 & 0.467 & 0.433 \\
\hline Xishuangbanna & 1.000 & 1.000 & 1.000 & 1.000 & 0.800 \\
\hline Dali & 0.804 & 1.000 & 0.939 & 1.000 & 1.000 \\
\hline Dehong & 0.675 & 0.815 & 1.000 & 1.000 & 1.000 \\
\hline Nujiang & 1.000 & 1.000 & 1.000 & 1.000 & 1.000 \\
\hline Diqing & 1.000 & 1.000 & 1.000 & 1.000 & 1.000 \\
\hline
\end{tabular}

Recall that the SCPI can be decomposed into pure technical efficiency (PTE) and scale efficiency (SE). We now turn to a brief description of the PTE and SE of sixteen cities. As shown in Fig. 3, the difference among sixteen cities in SCPI is mainly due to the difference in PTE; Honghe had the lowest PTE, with a value of 0.362 in 2012. Moreover, both the PTE and SE of Nujiang and Diqing consistently achieved $100 \%$ performance and attained the technological frontier. Although Kunming 
had the lowest SE values, Kunming's SE has demonstrably increased slightly and is approaching the technological frontier.

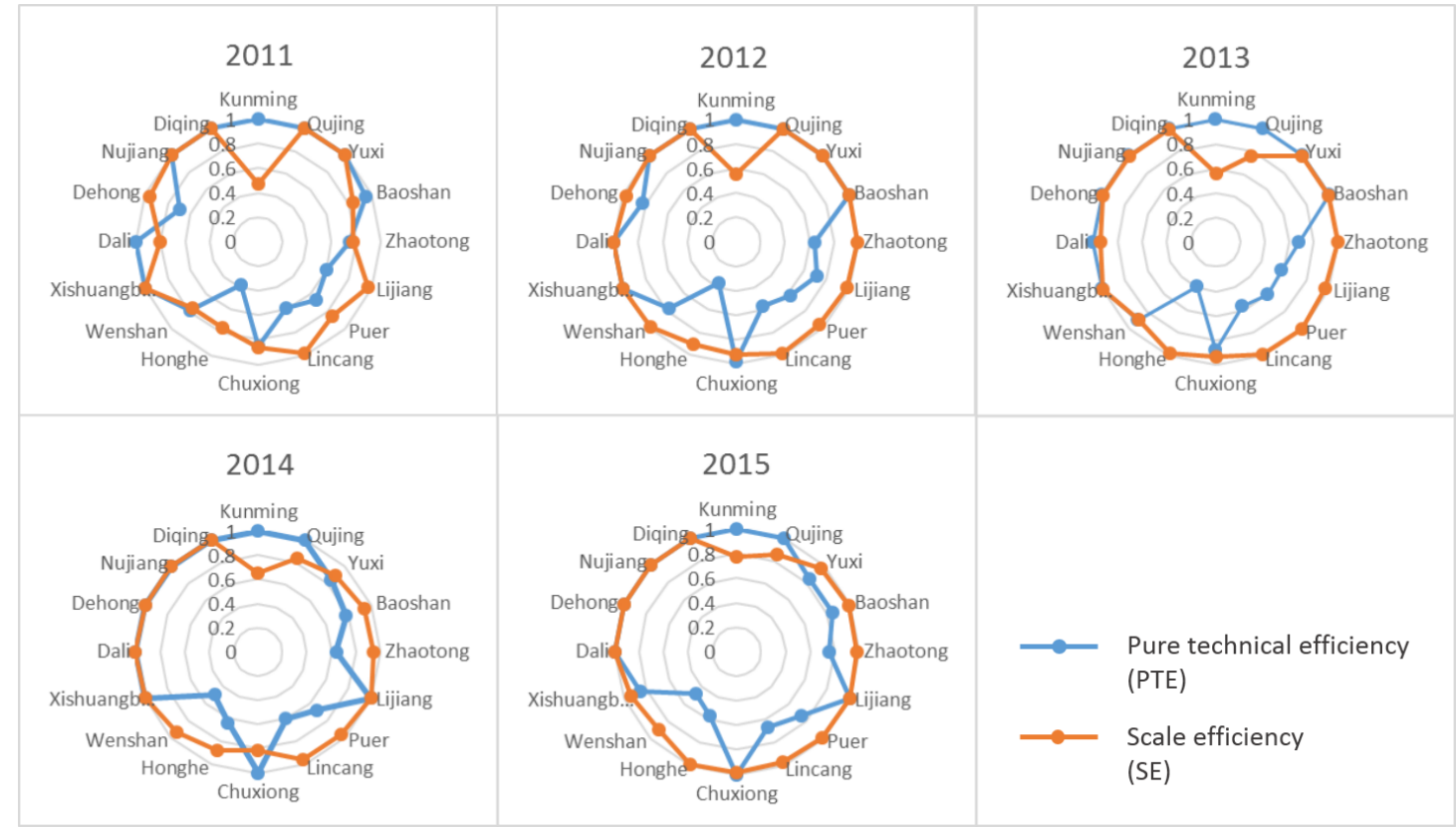

Fig. 3. The decomposition of SCPI for sixteen cities.

\subsection{Dynamic carbon emissions performance in logistics}

Table 6 illustrates the dynamic carbon emissions performance index (DCPI) for sixteen cities within Yunnan Province for the period 2011 to 2015. On average, the DCPI is 0.941 , indicating the dynamic logistics carbon emissions performance of all these cities decreased by approximately $5.9 \%$ from 2011 to 2015 . This result implies that, on average, the ratio of target carbon intensity to actual carbon intensity has decreased by 5.9\% per year over the research period. Longitudinally, only 2011-2012 shows improvement in performance, with a value of 1.113 , whereas the other periods reflect regression.

Turning to the city-by-city results, the DCPI of six cities (Kunming, Lijiang, Chuxiong, Honghe, Dali and Dehong) improved, and of these, Kunming has the highest DCPI value (1.054). However, the DCPI of other cities has decreased, especially in Yuxi, which has the lowest DCPI value (0.756). Yuxi clearly had the lowest DCPI value in 2013-2014 (0.243). According to Yunnan Statistical Yearbook, the lowest DCPI value can be explained by the sharp decrease of gross product in Yuxi's 
logistics, falling from 35.79 million yuan in 2013 to 18.96 million yuan in 2014, while its investment in fixed assets and carbon emissions in logistics continued to grow. Declining productivity and growing inputs caused the deterioration in Yuxi's logistics carbon emissions performance during the research period.

Table 6 Dynamic logistics carbon emissions performance index (DCPI) for sixteen cities.

\begin{tabular}{|c|c|c|c|c|c|}
\hline City & 2011-2012 & $2012-2013$ & 2013-2014 & 2014-2015 & Mean \\
\hline Kunming & 1.148 & 1.060 & 1.006 & 1.007 & 1.054 \\
\hline Qujing & 1.161 & 0.596 & 0.692 & 0.916 & 0.814 \\
\hline Yuxi & 1.231 & 1.118 & 0.243 & 0.976 & 0.756 \\
\hline Baoshan & 1.295 & 0.982 & 0.656 & 0.990 & 0.953 \\
\hline Zhaotong & 1.134 & 1.006 & 0.744 & 1.059 & 0.974 \\
\hline Lijiang & 1.061 & 0.709 & 1.575 & 0.900 & 1.016 \\
\hline Puer & 1.013 & 1.017 & 1.050 & 0.889 & 0.990 \\
\hline Lincang & 0.940 & 1.015 & 1.018 & 0.920 & 0.972 \\
\hline Chuxiong & 1.276 & 0.905 & 0.882 & 1.088 & 1.026 \\
\hline Honghe & 1.083 & 0.987 & 1.060 & 0.905 & 1.006 \\
\hline Wenshan & 1.298 & 0.936 & 0.507 & 0.805 & 0.839 \\
\hline Xishuangbanna & 0.840 & 0.970 & 0.949 & 0.631 & 0.836 \\
\hline Dali & 1.744 & 0.803 & 0.885 & 0.970 & 1.047 \\
\hline Dehong & 1.051 & 0.960 & 0.965 & 1.117 & 1.021 \\
\hline Nujiang & 0.929 & 0.810 & 0.892 & 0.996 & 0.904 \\
\hline Diqing & 0.888 & 0.794 & 1.061 & 0.922 & 0.912 \\
\hline Mean & 1.113 & 0.906 & 0.830 & 0.936 & 0.941 \\
\hline
\end{tabular}

To investigate the source of logistics-related carbon emissions performance change, the DCPI can be decomposed into efficiency change (ECH) and technology change (TCH) components. Fig. 4 gives information about the average ECH and TCH values for each city from 2011-2015. Most cities experienced an increase in ECH, i.e., the values of ECH are greater than 1. Honghe's ECH is the highest (1.181) in the sample, which indicates that the logistics in Honghe have moved towards 
the contemporaneous technology frontier over the study period and reflects catch-up efficiency in carbon emissions performance. Regarding $\mathrm{TCH}$, all sixteen cities exhibited a state of technological decline. As shown in Fig. 4, the TCH values of all sixteen cities are lower than 1, which suggests a lack of technological innovation in low-carbon technology within the logistics industry during the research period.

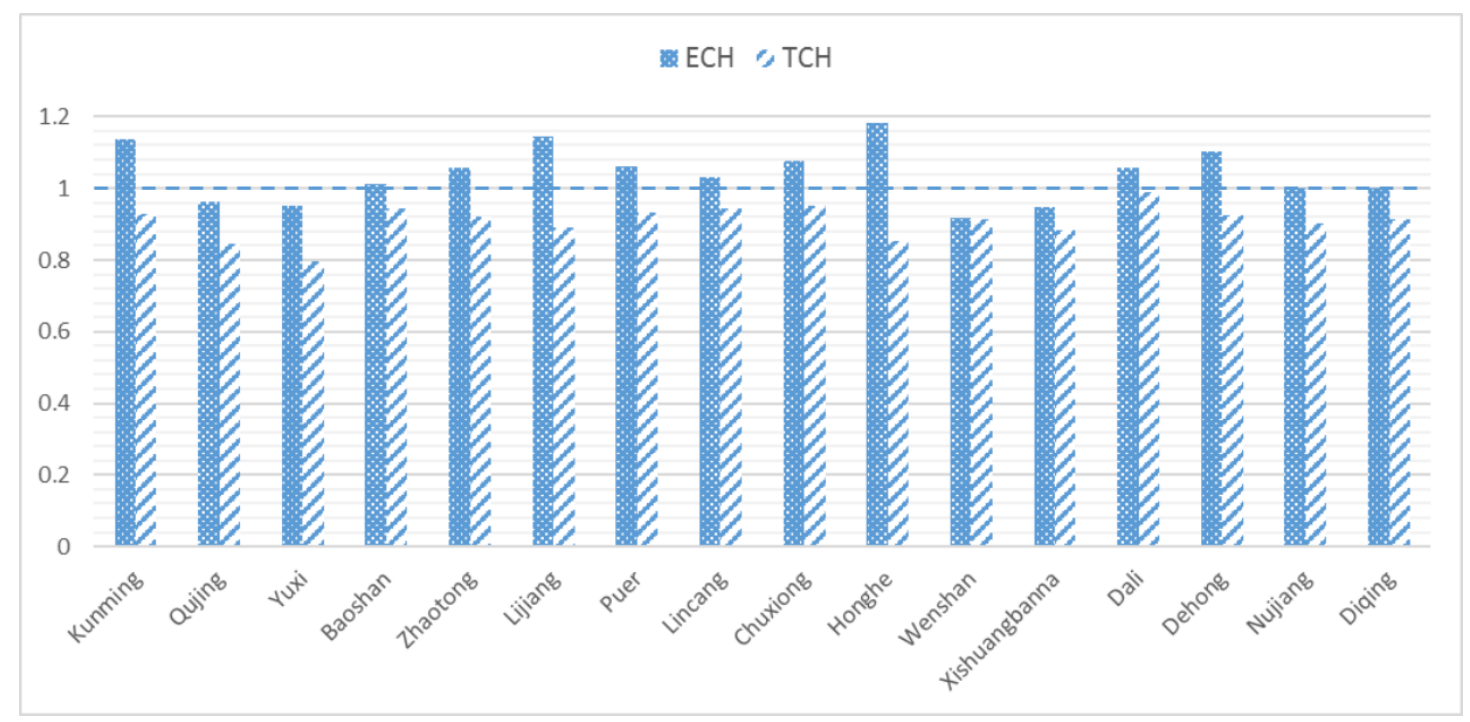

Fig. 4. The decomposition of DCPI (2011-2015) for sixteen cities.

\subsection{Regression analysis}

The main purpose of this section is testing the driving factors of carbon emissions performance in logistics. As the results in Table 7 show, the coefficients of five driving factors and their significance vary. The positive correlation coefficient between SCPI and economic development is 0.149 , indicating that a $1 \%$ increase in economic growth would lead to a $0.149 \%$ increase in SCPI. However, the relationship between DCPI and economic development is not significant. Regarding energy intensity, the regression results show that the variable is negatively related to SCPI and DCPI, with a significance of $1 \%$ and $10 \%$, respectively, implying that the energy consumption per unit of logistics added value is higher and that the SCPI and DCPI values are lower because logistics growth is accompanied by more energy consumption and leads to more carbon emissions. Urbanization level is shown to be significantly negatively correlated to SCPI, implying that a higher urbanization 
level results in a lower SCPI. It is generally true that the rapid development of urbanization and population have led to increased demand for energy and materials, resulting in substantial carbon emissions in industry, including logistics. The endowment structure coefficient is significantly negatively related to SCPI and DCPI, with both being significant at the $1 \%$ level, indicating that if the endowment structure is higher, i.e., the logistics type is capital-intensive with more carbon emissions, the SCPI and the DCPI are lower. The technological progress shows a negatively related coefficient to SCPI, which suggests that the environmental technology has not been effective in improving the logistics carbon emissions performance.

Table 7 Tobit regression analysis.

\begin{tabular}{lll}
\hline & SCPI & DCPI \\
\hline Economic development & $0.149^{* * *}$ & 0.043 \\
& $(0.000)$ & $(0.270)$ \\
Energy intensity & $-0.051^{* * *}$ & $-0.030^{*}$ \\
& $(0.000)$ & $(0.110)$ \\
Urbanization level & $-0.706^{* *}$ & -0.397 \\
Endowment structure & $(0.069)$ & $(0.495)$ \\
& $-0.00)^{* * *}$ & $-0.001^{* * *}$ \\
Technological progress & $(0.006)$ & $(0.019)$ \\
Constant & $-0.019^{* * *}$ & -0.001 \\
& $(0.000)$ & $(0.908)$ \\
& $1.005^{* * *}$ & $1.173^{* * *}$ \\
\hline
\end{tabular}

Note: * Denotes statistical significance at the $10 \%$ level; $* *$ denotes statistical significance at the $5 \%$ level; and $* * *$ denotes statistical significance at the $1 \%$ level.

\section{Conclusions}

This study analyses carbon emissions performance in the logistics industry from both a static and a dynamic perspective by examining sixteen cities within Yunnan Province; then uses the Tobit model to capture the driving factors of the sector's carbon emissions performance. This study provides two main contributions: (1) it attempts to investigate carbon emissions performance in logistics at the city level, and (2) it examines sixteen cities in Yunnan Province as a case study to measure their carbon emissions performance in the logistics industry.

The empirical study reveals that the logistics-related carbon emissions of sixteen cities have 
increased from 2011 to 2015; Kunming had the highest carbon emissions levels in logistics, with 457.52 ( $10^{4}$ tons $)$ in 2011 and 522.16 (10 tons) in 2015. Regarding logistic carbon emissions performance, although the SCPI in some cities is not strong, such as in Kunming and Honghe, their DCPI has significantly improved, mainly driven by efficiency change (the catch-up effect). The SCPI of Nujiang and Diqing attained the technological frontier throughout the period under examination, whereas their DCPI values decreased due to the low value of efficiency change (ECH) and technology change (TCH). The average DCPI in all cities decreased by approximately $5.9 \%$ due to a decline in $\mathrm{TCH}$. In terms of driving factors, the economic development factor is found to be positively and significantly related to static carbon emissions performance, whereas others indicate negative and significant relationships. Energy intensity and endowment structure were the main impact factors on DCPI and showed negative relationships.

Based on the above conclusions, some policy recommendations are provided for achieving a low-carbon economy in the logistics industry. First, the factors related to economic development greatly increased carbon emissions performance; thus, more attention should be focused on lowcarbon development in logistics by implementing relevant regulations, for example, by incorporating "green logistics" in government plans. Second, since energy intensity, endowment structure and urbanization level negatively impact logistics carbon emissions performance, a shift in the fuel consumption model should be stressed in the logistics sector, and the consciousness of low-carbon processes should be addressed to actively guide residents towards low-carbon commuting. Third, logistics-related technological innovations should be further promoted, not only in logistics equipment manufacturing but also in logistics planning and management, such as reducing freight transport intensity, increasing vehicle utilization and decarbonising warehousing operations. Fourth, the statistical data in logistics, especially at the city level, need to be improved and updated, as well-functioning logistics databases can be of great assistance for further empirical research.

This paper also has several limitations. The empirical study is based on data from 2011 to 2015 , due to limited energy data for the sixteen cities studied. As a result, the driving factors with DCPI are not sufficiently significant. Thus, future research should consider a longer period of study. Furthermore, the empirical study focuses on the logistics industry, and more specific logistics factors 
need to be considered in future studies.

\section{Acknowledgements}

This work is supported by the National Natural Science Foundation of China (NSFC No.71862035).

\section{References}

Banker, R.D., Charnes, A., Cooper, W.W., 1984. Some models for estimating technical and scale inefficiencies in Data Envelopment Analysis. Manage. Sci. 30(9), 1078-1092.

Behnke, M., Kirschstein, T., 2017. The impact of path selection on GHG emissions in city logistics. Transport. Res. E-Log. 106, 320-336.

Cai, B., Guo, H., Cao, L., Guan, D., Bai, H., 2018. Local strategies for China’s carbon mitigation: An investigation of Chinese city-level $\mathrm{CO}_{2}$ emissions. J. Clean. Prod. 178, 890-902.

Caves, D.W., Christensen, L.R., Diewert, W.E., 1982. The economic theory of index numbers and the measurement of input, output, and productivity. Econometrica 50(6), 1393-1414.

Cheng, Z., Shi, X., 2018. Can industrial structural adjustment improve the total-factor carbon emission performance in China? Int. J. Environ. Res. Public Health 15(10), 2291.

Dong, K., Sun, R., Li, H., Jiang, H., 2017. A review of China’s energy consumption structure and outlook based on a long-range energy alternatives modeling tool. Petrol. Sci. 14(1), 214-227.

Emrouznejad, A., Yang, G., 2016. $\mathrm{CO}_{2}$ emissions reduction of Chinese light manufacturing industries: A novel RAM-based global Malmquist-Luenberger productivity index. Energy Policy 96, $397-410$

Fare, R., Grosskopf, S., Lovell, C.A.K., Pasurka, C., 1989. Multilateral productivity comparisons when some outputs are undesirable: a nonparametric approach. Rev. Econ. Stat. 71(1), 90-98.

Fare, R., Grosskopf, S., 2003. New directions: efficiency and productivity. Stud. Product. Effi. 17, 979995.

Fare, R., Grosskopf, S., Norris, M., Zhang, Z., 1994. Productivity growth, technical progress, and efficiency change in industrialized countries. Am. Econ. Rev. 84(1), 66-83. 
Fei, R., Lin, B., 2016. The integrated efficiency of inputs-outputs and energy- $\mathrm{CO}_{2}$ emissions performance of China’s agricultural sector. Renew. Sust. Energ. Rev. 75, 668-676.

Feng, C., Wang, M., Liu, G., Huang, J., 2017. Green development performance and its influencing factors: A global perspective. J. Clean. Prod. 144, 323-333.

Houshyar, E., Mahmoodi-Eshkaftaki, M., Azadi, H., 2017. Impacts of technological change on energy use efficiency and GHG mitigation of pomegranate: Application of dynamic data envelopment analysis models. J. Clean. Prod. 162, 1180-1191.

Hu, X., Liu, C., Si, T., 2017. Total factor carbon emission performance measurement and development. J. Clean. Prod. 142, 2804-2815.

Li, J., Huang, X., Kwan, M.P., Yang, H., Chuai, X., 2018. The effect of urbanization on carbon dioxide emissions efficiency in the Yangtze River Delta, China. J. Clean. Prod. 188, 38-48.

Li, X., Tang, B., 2017. Incorporating the transport sector into carbon emission trading scheme: an overview and outlook. Nat. Hazards 88(2), 683-698.

Lin, B., Du, K., 2015. Modeling the dynamics of carbon emission performance in China: A parametric Malmquist index approach. Energy Econ. 49, 550-557.

Lin, B., Fei, R., 2015. Regional differences of $\mathrm{CO}_{2}$ emissions performance in China's agricultural sector: A Malmquist index approach. Eur. J. Agron. 70, 33-40.

Malmquist, S., 1953. Index numbers and indifference surfaces. Trab Estad. 4(1), 209-242.

Mariano, E.B., Gobbo Jr, J.A., De Castro Camioto, F., Do Nascimento Rebelatto, D.A., 2017. $\mathrm{CO}_{2}$ emissions and logistics performance: a composite index proposal. J. Clean. Prod. 163, 166-178.

Mckinnon, A., Piecyk, M., 2012. Setting targets for reducing carbon emissions from logistics: current practice and guiding principles. Carbon Manag. 3(6), 629-639.

Mi, Z., Guan, D., Liu, Z., Liu, J., Viguié, V., Fromer, N., Wang, Y., 2019a. Cities: The core of climate change mitigation. J. Clean. Prod. 207, 582-589.

Mi, Z., Meng, J., Guan, D., Shan, Y., Song, M., Wei, Y., Liu, Z., Hubacek, K., 2017. Chinese $\mathrm{CO}_{2}$ emission flows have reversed since the global financial crisis. Nat.Commun. 8(1), 1712.

Mi, Z., Zhang, Y., Guan, D., Shan, Y., Liu, Z., Cong, R., Yuan, X., Wei, Y., 2016. Consumption-based emission accounting for Chinese cities. Appl. Energ. 184, 1073-1081. 
Mi, Z., Zheng, J., Meng, J., Zheng, H., Li, X., Coffman, D.M., Woltjer, J., Wang, S., Guan, D., 2019 b. Carbon emissions of cities from a consumption-based perspective. Appl. Energ. 235, 509-518.

Molinos-Senante, M., Sala-Garrido, R., Hernández-Sancho, F., 2016. Development and application of the Hicks-Moorsteen productivity index for the total factor productivity assessment of wastewater treatment plants. J. Clean. Prod. 112(2), 3116-3123.

National Bureau Statistics of China, 2018. China Statistical Yearbook. China Statistical Press, Beijing.

Saglam, U., 2018. A two-stage performance assessment of utility-scale wind farms in Texas using data envelopment analysis and Tobit models. J. Clean. Prod. 201, 580-598.

Seiford, L. M., Zhu, J., 2002. Modeling undesirable factors in efficiency evaluation. Eur. J. Oper. Res. 142(1), 16-20.

Shan, Y., Guan, D., Zheng, H., Ou, J., Li, Y., Meng, J., Mi, Z., Liu, Z., Zhang, Q., 2018. China $\mathrm{CO}_{2}$ emission accounts 1997-2015. Sci. data 5, 170201.

Tian, X., Geng, Y., Zhong, S., Wilson, J., Gao, C., Chen, W., Yu, Z., Hao, H., 2018. A bibliometric analysis on trends and characters of carbon emissions from transport sector. Transport. Res. DTR. E. 59, 1-10.

Tobin, J., 1958. Estimation of relationships for limited dependent variables. Econometrica 26(1), 24-36.

Wang, D., Li, T., 2018. Carbon Emission Performance of Independent Oil and Natural Gas Producers in the United States. Sustainability 10(1), 1-18.

Wang, S., Ma, Y., 2018. Influencing factors and regional discrepancies of the efficiency of carbon dioxide emissions in Jiangsu, China. Ecol. Indic. 90, 460-468.

Wang, J., Shi, Y., Zhang, J., 2017. Energy efficiency and influencing factors analysis on Beijing industrial sectors. J. Clean. Prod. 167, 653-664.

Wang, X., Du, L., 2017. Carbon emission performance of China's power industry: regional disparity and spatial analysis. J. Ind. Ecol. 21(5), 1323-1332.

Wu, F., Fan, L., Zhou, P., Zhou, D., 2012. Industrial energy efficiency with $\mathrm{CO}_{2}$ emissions in China: A nonparametric analysis. Energy Policy 49(1), 164-172.

Wu, T., Chen, Y., Shang, W., Wu, J., 2018. Measuring energy use and $\mathrm{CO}_{2}$ emission performances for APEC economies. J. Clean. Prod. 183, 590-601. 
Yan, D., Lei, Y., Li, L., Song, W., 2017. Carbon emission efficiency and spatial clustering analyses in China's thermal power industry: Evidence from the provincial level. J. Clean. Prod. 156, 518527.

Zhang, L., Kou, C., Zheng, J., Li, Y., 2018. Decoupling Analysis of $\mathrm{CO}_{2}$ Emissions in Transportation Sector from Economic Growth during 1995-2015 for Six Cities in Hebei, China. Sustainability $10(11), 4149$.

Zhang, N., Choi, Y., 2013a. A comparative study of dynamic changes in $\mathrm{CO}_{2}$ emission performance of fossil fuel power plants in China and Korea. Energy Policy 62(9), 324-332.

Zhang, N., Choi, Y., 2013b. Total-factor carbon emission performance of fossil fuel power plants in China: A metafrontier non-radial Malmquist index analysis. Energy Econ. 40(2), 549-559.

Zhang, N., Zhou, P., Choi, Y., 2013. Energy efficiency, $\mathrm{CO}_{2}$ emission performance and technology gaps in fossil fuel electricity generation in Korea: A meta-frontier non-radial directional distance functionanalysis. Energy Policy 56(2), 653-662.

Zhang, N., Zhou, P., Kung, C.C., 2015. Total-factor carbon emission performance of the Chinese transportation industry: A bootstrapped non-radial Malmquist index analysis. Renew. Sust. Energ. Rev. 41, 584-593.

Zhou, G., Chung, W., Zhang, X., 2013. A study of carbon dioxide emissions performance of China's transport sector. Energy 50(1), 302-314.

Zhou, G., Chung, W., Zhang, Y., 2014. Measuring energy efficiency performance of China's transport sector: A data envelopment analysis approach. Expert Syst. Appl. 41(2), 709-722.

Zhou, P., Ang, B., Han, J., 2010. Total factor carbon emission performance: a Malmquist index analysis. Energ. Econ. 32(1), 194-201.

Zhou, P., Wang, H., 2012. Energy and $\mathrm{CO}_{2}$ emission performance in electricity generation: A non-radial directional distance function approach. Eur. J. Oper. Res. 221(3), 625-635.

Zhou, Z., Liu, C., Zeng, X., Jiang, Y., Liu, W., 2018. Carbon emission performance evaluation and allocation in Chinese cities. J. Clean. Prod. 172, 1254-1272. 